Solid State Communications, Vol. 13, pp. 979-981, 1973. Pergamon Press. Printed in Great Britain

\title{
RADIO AND THERMOLUMINESCENCE STUDIES IN CSI DOPED WITH F CENTERS
}

\author{
J.P. Pellaux, T. Sidler, A. Nouailhat* and M.A. Aegerter \\ Institut de Physique, Université de Neuchâtel, Switzerland
}

(Received 30 June 1973 by F. Bassani)

\begin{abstract}
Radioluminescence, thermoluminescence and u.v. excitation measurements in CsI additively colored crystals show a new luminescent component located at $2.5 \mathrm{eV}$. This is attributed to the radiative recombination of $V_{k}$ centers with $\mathrm{F}$ centers. Another new component at $2.72 \mathrm{eV}$ is observed only under u.v. excitation of $5.14 \mathrm{eV}$. This is related to the radiative recombination of localised excitons at $\mathrm{F}^{+}$center sites ( $\alpha$ band).
\end{abstract}

SINGLE crystals of CsI having a low concentration of impurities such as $\mathrm{Mn}^{2+}$ (100 ppm in the melt) or $\mathrm{Na}^{+}$ ( $20 \mathrm{ppm}$ in the crystal) have been additively colored in cesium atmosphere with the usual van Doorn's technique. They were further quenched between two copper blocks after $30 \mathrm{sec}$ heating at $500^{\circ} \mathrm{C}$. The F center concentration was typically of the order of $10^{17} \mathrm{~cm}^{-3}$. The presence of $\mathrm{Mn}^{2+}$ or $\mathrm{Na}^{+}$impurities, which at low temperature are electron traps, was in origin thought to be necessary in order to create a sufficient amount of $V_{k}$ centers. $^{1}$

We have studied the recombination processes under ionizing irradiation ( $\beta$ source $\mathrm{Sr}^{90} 8 \mathrm{mCi}$ ) in two different temperature regions. For $T<50^{\circ} \mathrm{K}$, the $V_{k}$ centers are self-trapped and we observe only the well known intrinsic emission at $3.67 \mathrm{eV} .^{2}$ At higher temperature the $V_{k}$ centers are mobile and additional huminescence occurs. Figure 1 shows the spectral analysis of the radioluminescence observed at $90^{\circ} \mathrm{K}$. Besides the intrinsic emission at $3.67 \mathrm{eV}$, a new component appears at $2.5 \mathrm{eV}$ with a half-width of $0.52 \mathrm{eV}$. We found that its intensity is an increasing function of the $F$ center concentration. Figure 1 shows also that, starting with a given $F$ center concentration, the $2.5 \mathrm{eV}$ luminescence intensity decreases after bleaching in the $F$-absorption

* Visiting scientist on leave from the Institut National des Sciences Appliquées (INSA) Lyon, France. band (conversion $2 \mathrm{~F}+h \nu_{F}=\mathrm{F}^{+}+\mathrm{F}^{-}$) ) $^{3}$ the intensity of the intrinsic emission at $3.67 \mathrm{eV}$ being enhanced by the same relative amount. The emission intensity of both components can be restored to their initial values after a thermal annealing near $300^{\circ} \mathrm{K}$. The temperature dependence of the intensity of the $2.5 \mathrm{eV}$ emission is similar to that of the radiative recombination of the localized excitons associated with impurities such as $\mathrm{Na}^{+}{ }^{2}$ In particular the emission intensity is zero below $50^{\circ} \mathrm{K}$ and presents a sharp increase at the temperature at which the $V_{k}$ centers become mobile. These experiments show that the $2.5 \mathrm{eV}$ emission is unambiguously related to the radiative recombination of mobile $V_{k}$ centers created by the ionizing radiation with $F$ centers already present in the crystal. This process can thus be regarded as the recombination of a localized exciton in the neighbourhood of an $\mathrm{F}^{+}$center. This emission process is evidently in competition with intrinsic recombination mechanism, $\left[e^{-}+V_{k} \rightarrow h \nu\right.$ $(3.67 \mathrm{eV})]$.

Thermoluminescence of a $\operatorname{CsI}\left(\mathrm{Na}^{+}\right)$crystal $X$ or $\beta$ irradiated at $T<50^{\circ} \mathrm{K}$ presents the glow peaks associated with the thermal migration of $V_{k}$ centers. ${ }^{1}$ The spectral analysis shows two main components which are the same as in Fig. 1, one located at $2.5 \mathrm{eV}$ and the other at $3.67 \mathrm{eV}$. The characteristic emission of the radiative recombination of mobile $V_{k}$ centers with impurities $\left(\mathrm{Na}^{+}: 2.95 \mathrm{eV}\right)$ also appears however 


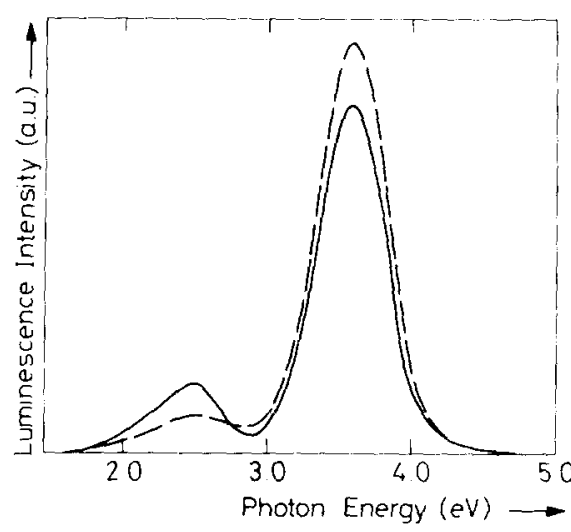

FIG. 1. Spectral analysis of the luminescence observed under $\beta$ irradiation at $T=90^{\circ} \mathrm{K}$ in CsI containing $F$ centers. measured with a quenched crystal, _- $\ldots$ measured after partial bleaching of the $F$ band ( $F \rightarrow F^{-}$conversion).

with a lower intensity. Figure 2 shows the relative variation of the different emission intensities as a function of temperature for a heating rate of $4^{\circ} \mathrm{K} / \mathrm{min}$. This is different from the glow curve of reference 1 because the kinetics of the recombination mechanisms are different since $F$ centers take part in them.

The appearance of the $2.5 \mathrm{eV}$ emission confirms the proposed recombination mechanism between mobile $V_{k}$ centers and $\mathrm{F}$ centers.

The presence of the $3.67 \mathrm{eV}$ emission is strongly related to the presence of $\mathrm{F}^{-}$centers created during the ionizing irradiation at LHeT $(F+$ (electron-hole) pair $\rightarrow \mathrm{F}^{-}+V_{k}$ ). A similar analysis of the glow curves recorded after a complete infrared irradiation bleaching of the $\mathrm{F}^{-}$centers just after the ionizing irradiation shows only the emission at $2.5 \mathrm{eV}$ and those associated with the impurities at $2.95 \mathrm{eV}$. The shapes of these glow curves are not changed but their intensities are reduced. These experiments clearly indicate that the appearance of the $3.67 \mathrm{eV}$ luminescence is due to a mechanism which ionizes the $\mathrm{F}^{-}$ centers formed during irradiation. Two processes can be visualised:

(a) Autoionization of an $\mathrm{F}^{-}$center by the recombination of one of its electrons with a $V_{k}$ center, the energy produced being used for the ionization of the second electron.

$V_{k}+\mathrm{F}^{-} \rightarrow\left(e^{-}+V_{k}\right)_{\text {not rad }}+\mathrm{F} \rightarrow \mathrm{F}^{+}+e^{-}$

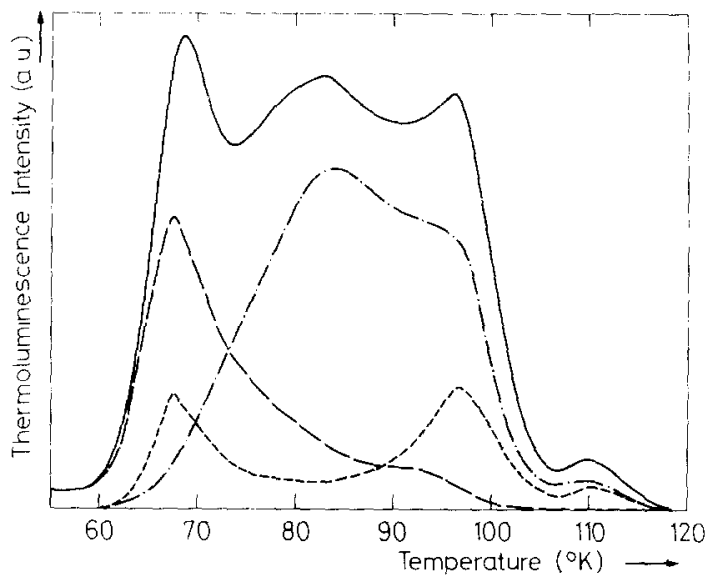

FIG. 2. Relative intensity of the different glow peaks measured as a function of temperature for a heating rate of $4^{\circ} \mathrm{K} / \mathrm{min}$ after a $30 \mathrm{mn} \beta$ irradiation at LHeT. - - - - $3.67 \mathrm{eV}(338 \mathrm{~nm})$ emission. - - - $-2.50 \mathrm{eV}$ $(495 \mathrm{~nm})$ emission.___ $-2.95 \mathrm{eV}(420 \mathrm{~nm})$

emission._- total emission (experimental). The sum of the three spectral emission intensities is in good agreement with the plain curve.

$e^{-}+V_{k} \rightarrow h v(3.67 \mathrm{eV})$

This process is finally equivalent to the ionization of $F$ center by excitation in the $\beta$ band. ${ }^{4}$

(b) Ionization due to the partial absorption of the $2.5 \mathrm{eV}$ emission by the broad $\mathrm{F}^{-}$absorption.

$h \nu(2.5 \mathrm{eV})+\mathrm{F}^{-} \rightarrow \mathrm{F}+e^{-}$

followed by intrinsic recombination

$e^{-}+V_{k} \rightarrow h \nu(3.67 \mathrm{eV})$.

Inspection of Fig. 2 shows that process (a) is prevailing, at least for the first glow peak at $65^{\circ} \mathrm{K}$.

Ultraviolet excitation $(6.5 \mathrm{eV}>h v>4 \mathrm{eV})$ of a quenched additively colored crystal shows in the visible region of the spectrum only the well known intrinsic luminescence $(3.67 \mathrm{eV})$ due to free exciton recombination, and the additionnal luminescence due to exciton recombination at impurity sites, which are characteristic of an uncolored specimen. ${ }^{2}$ The fact that the $F$ centers here do not play a role in the luminescence, in spite of the presence of an important $\beta$ band at $5.5 \mathrm{eV}$, is not surprising because the excited center undergoes autoionization ${ }^{4}$ resulting in a bare negative ion vacancy and an electron in the conduction band. After a partial bleaching of the $F$ centers performed at 


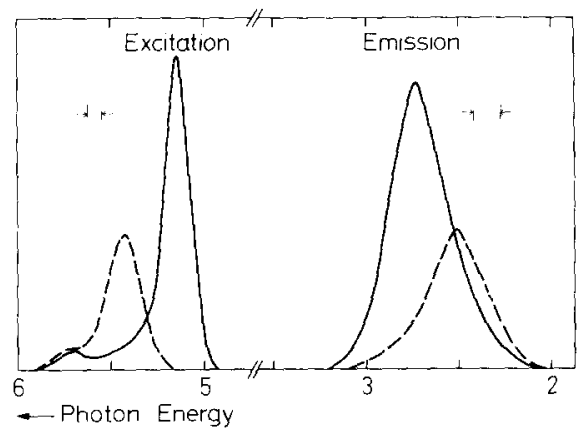

FIG 3. u.v. excitation spectra and emission spectra of an additively colored CsI crystal measured at LHeT after partial bleaching of the $\mathrm{F}$ band $\left(\mathrm{F} \rightarrow \mathrm{F}^{-}\right.$conversion) at $90^{\circ} \mathrm{K}$. Excitation spectra - emission measured at 2.72._._. emission measured at 2.50. Emission spectra ___ excitation at 5.17. _... - excitation at 5.45 .

$90^{\circ} \mathrm{K}$ the $\beta$ band decreases and the $\alpha$ band appears in the u.v. region. Optical excitation of this band $(5.17 \mathrm{eV})$ at $\mathrm{LHeT}$ produces a new luminescent component centered at $2.7 \mathrm{eV}$ with a half-width of $0.37 \mathrm{eV}$. Moreover the $2.5 \mathrm{eV}$ emission can also be produced by excitation at $5.45 \mathrm{eV}$ in correspondence to excited states of the $\mathrm{F}^{+}$centers already observed by Fröhlich and Mahr. ${ }^{5}$ Figure 3 shows the excitation and emission spectra related to these new components when a sufficient number of $\mathrm{F}^{+}$centers is present.

We may conclude that all luminescence emissions previously observed by irradiation and thermal stimulation appear also in u.v. excitation, but in this case one observes in addition a typical emission due to relaxed $\alpha$ centers $(2.72 \mathrm{eV})$. It is consistent with the localized model of the $\mathrm{F}^{+}$center $^{6}$ that different relaxations occur, depending on the position of the hole produced by the transition relative to the negative ion vacancy. For excitation in the $\alpha$-band the hole is next to the vacancy while in the higher excited bands the hole is farther and its relaxation is that typical of the $V_{k}$ center thus producing the $V_{k}+\mathrm{F}$ recombination as shown in Fig. 3 .

Acknowledgements - The authors are indebted to Professor F. Bassani for fruitful discussions during his stay in Neuchâtel as a CICP professor (1972-73). This work has been supported by the Swiss National Foundation for Scientific Research (FNSRS).

\section{REFERENCES}

1. SidLER T., PEllaUX J.P., NOUAILHAT A. and AEGERTER M.A. Solid State Commun. 13, (1973).

2. LAMATSCH H., ROSSEL J. and SAURER E., Phys. Status Solidi (b) 48, 311 (1971).

3. We use in this letter the nomenclature proposed by SONDER E. and SIBLEY W.A. in Ch. 4 of Point Defects in Solids, (Edited by CRAWFORD J.H. and SLIFKIN L.M.) Plenum Press, New York (1972).

4. FUCHS R., Phys. Rev. 111, 387 (1958).

5. FRÖHLICH D. and MAHR H., Phys. Rev. 144, 720 (1966).

6. BASSANI F. and INCHAUSPE N., Phys. Rev. 105, 819 (1957).

Des mesures de radioluminescence, thermoluminescence et d'excitation u.v. présentent dans le iodure de césium coloré additivement une nouvelle composante luminescente centrée à $2.5 \mathrm{eV}$. Nous l'attribuons à la recombinaison radiative de centres $V_{k}$ avec des centres $\mathrm{F}$. Une autre émission, située à $2.72 \mathrm{eV}$ et excitée par u.v. à $5.14 \mathrm{eV}$ est liée à la recombinaison radiative d'excitons localisés sur des centres $\mathrm{F}^{+}$. 